\title{
Rates of Noninsulin-mediated Glucose Uptake Are Elevated in Type II Diabetic Subjects
}

Alain D. Baron, Orville G. Kolterman, Jo Bell, Lawrence J. Mandarino, and Jerrold M. Olefsky

Department of Medicine, University of California, San Diego, La Jolla, California 92093

\begin{abstract}
Although insulin is extremely potent in regulating glucose transport in insulin-sensitive tissues, all tissues are capable of taking up glucose by facilitated diffusion by means of a noninsulinmediated glucose uptake (NIMGU) system. Several reports have estimated that in the postabsorptive state the majority of glucose disposal occurs via a NIMGU mechanism. However, these estimates have been either derived or extrapolated in normal humans. In the present study we have directly measured NIMGU rates in 11 normal (C) and 7 Type II noninsulin-dependent diabetic subjects (NIDDM; mean \pm SE fasting serum glucose, $249 \pm 24 \mathrm{mg} / \mathrm{dl}$ ). To accomplish this, the serum glucose was clamped at a desired level during a period of insulin deficiency induced by a somatostatin infusion (SRIF, $550 \mu \mathrm{g} / \mathrm{h}$ ). With a concomitant $\left[3-{ }^{3} \mathbf{H}\right]$ glucose infusion, we could isotopically quantitate glucose disposal rates $\left(\mathbf{R}_{d}\right)$ during basal (basal insulin present) and insulin-deficient (SRIF) conditions. With this approach we found that $(a)$ basal $R_{d}$ was greater in NIDDM than in $C, 274 \pm 31$ vs. $150 \pm 7 \mathrm{mg} / \mathrm{min}$, due to elevated hepatic glucose output, (b) NIMGU composes $75 \pm 5 \%$ of basal $R_{d}$ in $C$ and $71 \pm 4 \%$ in NIDDM, (c) NIDDMS have absolute basal NIMGU rates that are twice that of $C(195 \pm 23 \mathrm{vs} .113 \pm 8 \mathrm{mg} / \mathrm{min}, P<$ $0.05),(d)$ when $C$ were studied under conditions of insulin deficiency (SRIF infusion) and at a serum glucose level comparable to that of the NIDDM group ( $250 \mathrm{mg} / \mathrm{dl}$ ), their rates of NIMGU were the same as that of the NIDDM group (186 \pm 19 vs. 195 \pm 23 $\mathrm{mg} / \mathrm{min}$; NS). We conclude that (a) in the postabsorptive state, NIMGU is the major pathway for glucose disposal for both $\mathbf{C}$ and NIDDM; (b) for a given glucose level the efficiency of NIMGU (NIMGU $\div$ serum glucose level) is equal in $\mathbf{C}$ and NIDDM, but since basal $R_{d}$ is elevated in NIDDMs their $a b-$ solute basal rates of NIMGU are higher; and (c) elevated basal rates of NIMGU in NIDDM may play a role in the pathogenesis of the late complications of diabetes.
\end{abstract}

\section{Introduction}

In vivo glucose uptake can occur via two mechanisms, namely, insulin-mediated glucose uptake (IMGU) ${ }^{1}$ and noninsulin-me-

This work was presented to the American Federation of Clinical Research, Carmel, CA, 7-10 February 1985.

Address reprint requests and correspondence to Dr. Olefsky, Veterans Administration Medical Center, Medical Research Service (V-111G), 3350 La Jolla Village Drive, San Diego, CA 92161. 1985.

Received for publication 12 March 1985 and in revised form 17 July

1. Abbreviations used in this paper: CNS, central nervous system; FFA, free fatty acid; IMGU, insulin-mediated glucose uptake; NIDDM, noninsulin-dependent diabetic subjects; NIMGU, noninsulin-mediated glucose uptake; $R_{a}$, rate of glucose appearance; $R_{d}$, rate of glucose disappearance; SRIF, somatostatin.

The Journal of Clinical Investigation, Inc.

Volume 76, November 1985, 1782-1788 diated glucose uptake (NIMGU). By definition, IMGU can occur only in insulin-sensitive tissues. On the other hand, NIMGU occurs in both insulin-sensitive and noninsulin-sensitive tissues. Although the literature abounds with reports of insulin-stimulated glucose disposal rates (IMGU) measured under different conditions and in different experimental groups, there is a paucity of literature relating to noninsulin-mediated glucose uptake in vivo $(1,2)$. This is surprising, since it has been estimated that the majority of glucose disposed of in the basal state is through NIMGU mechanisms $(3,4)$. Gottesman et al. (2) have estimated that in normal human subjects $75-85 \%$ of postabsorptive glucose uptake is noninsulin-mediated. This estimate was obtained by measuring glucose uptake isotopically while maintaining the serum glucose constant over a range of insulin levels. Glucose uptake at " 0 " insulin was estimated by plotting glucose disposal rates vs. plasma insulin concentrations and extrapolating to the intercept for glucose disposal at " 0 " insulin. This indirect method assumes linearity of glucose uptake, over insulin concentrations lower than those actually employed in the study, and therefore may not accurately reflect true rates of NIMGU.

Elucidation of the NIMGU system is important, as it is likely to be the major pathway of glucose uptake in the basal state. Furthermore, knowledge of NIMGU rates would allow for more precise estimates of strictly insulin-stimulated glucose uptake rates. Since overall insulin-stimulated glucose disposal, in fact, represents the sum of NIMGU and IMGU, if one had knowledge of that portion of overall insulin-stimulated glucose disposal which was NIMGU, then the difference would represent true insulin-stimulated glucose disposal. In addition, though it is well recognized that Type II diabetes is characterized by a marked impairment in insulin-stimulated glucose uptake, the status of NIMGU mechanisms in Type II diabetics is unknown.

Therefore, this study was undertaken to directly measure NIMGU in normal and Type II diabetic subjects over a large range of glucose concentrations. To accomplish this, glucose clamp studies were performed under conditions of insulin deficiency induced by a somatostatin infusion and glucose uptake rates determined isotopically. Each study was performed at each subject's respective fasting serum glucose level; control subjects were also studied under hyperglycemic conditions comparable to the diabetic group.

\section{Methods}

Materials. Porcine monocomponent insulin was generously supplied by Dr. Ronald Chance of Eli Lilly and Co. (Indianapolis, IN); ${ }^{125}$ I-Insulin and $\left[3-{ }^{3} \mathrm{H}\right]$ glucose were purchased from New England Nuclear (Boston, MA); bovine serum albumin (fraction V) was obtained from Armour Pharmaceutical Company (Tarrytown, NY); guinea pig anti-insulin antibody was kindly supplied by Dr. Edward Arquilla (Irvine, CA); somatostatin (cyclic form) was purchased from Bachem Incorporated (Torrance, CA).

Subjects. The study group consisted of 11 control subjects (normal OGTT) and 7 subjects with Type II diabetes mellitus as defined by the criteria of the National Diabetes Data Group (5). The clinical and met- 
abolic characteristics of the subjects are summarized in Table I. The fasting serum glucose and insulin levels represent the mean of five determinations done on consecutive days. The mean age \pm SEM of the diabetic subjects was $38 \pm 4$ yr compared with $34 \pm 2 \mathrm{yr}$ for the normal subjects, $P=$ NS. The relative weights of the Type II diabetics ranged from 0.92 to 1.23 and from 0.77 to 1.16 in the control group; with a mean $\pm S E M$ value of $1.07 \pm 0.14$ and $0.99 \pm 0.33$ for the diabetic and control subjects, respectively; $P=$ NS. The mean weight \pm SEM was $77 \pm 5$ and $63 \pm 3 \mathrm{~kg}$ in the diabetic group and control group, respectively; $P$ $<0.05$. After informed consent was obtained, all subjects were admitted to the University of California, San Diego, General Clinical Research Center, where they remained active to approximate their prehospital exercise level. Diabetic subjects were withdrawn from insulin for at least $10 \mathrm{~d}$ and from sulfonylureas for 3 wk before study. All subjects were chemically euthyroid and no subject had a concurrent disease or was ingesting pharmacological agents known to affect carbohydrate or insulin metabolism.

Diet. All subjects were placed on a weight-maintenance $(32 \mathrm{Kcal} / \mathrm{kg}$ per d) liquid formula diet, with three divided feedings containing $1 / 5$, $2 / 5$, and $2 / 5$ of the total daily calories given at 8 a.m., 12 a.m., and 5 p.m., respectively. The diet contained $45 \%$ carbohydrate, $40 \%$ fat, and $15 \%$ protein. All subjects equilibrated on this diet for at least $48 \mathrm{~h}$ before any studies were performed. Each study was performed on separate but consecutive days.

Oral glucose tolerance test. All control subjects underwent a 75-g oral glucose tolerance test after an overnight fast. Serum was obtained at $0,30,60,120$, and $180 \mathrm{~min}$ for measurement of glucose and insulin levels.

Somatostatin (SRIF) and glucose clamp studies. During each study, SRIF dissolved in $0.9 \%$ normal saline to which $2 \mathrm{ml}$ of patient's own serum was added and was infused at a rate of $550 \mu \mathrm{g} / \mathrm{h}$ starting at time 0 in both control and Type II diabetic (NIDDM) groups with no insulin replacement. In the control group, each subject underwent a 5-h glucose clamp study with the serum glucose held at or near the fasting level, by a variable rate exogenous glucose infusion. In addition, seven control subjects underwent a 4-h hyperglycemic clamp study with the serum glucose acutely raised and held at a mean level of $248 \pm 2 \mathrm{mg} / \mathrm{dl}$ (the mean fasting serum glucose for the NIDDM group). In the NIDDM group, each subject underwent a 5-h clamp study with the glucose level held at their respective fasting level (mean $\pm \mathrm{SE}, 253 \pm 24 \mathrm{mg} / \mathrm{dl}$; range, $163-348 \mathrm{mg} / \mathrm{dl}$ ).

Glucose disposal rates. $\mathrm{R}_{\mathrm{d}}$, the rate of overall glucose disappearance, and $R_{a}$, the rate of glucose appearance, were quantitated in the basal state and during each of the glucose clamp studies (6) by infusing [3${ }^{3} \mathrm{H}$ ]glucose in a primed, continuous manner. With this technique, 50 $\mu \mathrm{Ci}$ of the tracer is injected as a bolus, followed by a continuous infusion at the rate of $0.50 \mu \mathrm{Ci} / \mathrm{min}$. After a $60-\mathrm{min}$ equilibration period, blood samples were obtained at 20-min intervals, to determine both the serum glucose concentration and plasma specific activity. $\mathbf{R}_{\mathrm{a}}$ and $\mathbf{R}_{\mathbf{d}}$ were calculated with the Steele equations in their modified derivative form, since the tracer exhibits nonsteady-state kinetics under these conditions (7). The values for $R_{d}$ in the basal state and during the hyperglycemic studies were corrected for urinary glucose loss, to reflect the actual rate of endogenous glucose disposal.

Table I. Patient Characteristics

\begin{tabular}{cllllll}
\hline & Age & $\begin{array}{l}\text { Relative } \\
\text { body } \\
\text { weight }\end{array}$ & Weight & $\begin{array}{l}\text { Fasting } \\
\text { serum } \\
\text { glucose }\end{array}$ & $\begin{array}{l}\text { Fasting } \\
\text { serum } \\
\text { insulin }\end{array}$ & $\begin{array}{l}\text { Fasting serum } \\
\text { C-peptide }\end{array}$ \\
\hline $\begin{array}{c}\text { Control } \\
n=11\end{array}$ & $y r$ & & $k g$ & $m g / d l$ & $\mu u / m l$ & $p m o l / m l$ \\
$\begin{array}{c}\text { Diabetic } \\
n=7\end{array}$ & $38 \pm 4$ & 0.99 & $63 \pm 3$ & $90 \pm 1.7$ & $9.0 \pm 1.1$ & $0.55 \pm 0.06$ \\
\hline
\end{tabular}

Data are represented as mean \pm SEM.

* $P_{\mathrm{t}}<0.05 ; \ddagger P<0.001 ; \S P<0.01$.
Rates of NIMGU were measured during the period of SRIF-induced insulin deficiency, while the serum glucose was maintained at basal levels by a variable exogenous glucose infusion. Under these conditions, the maintenance of a steady-state serum glucose level is a result of several events (8), which should be noted. Thus, within $20 \mathrm{~min}$ of the onset of the SRIF infusion, $\mathbf{R}_{\mathrm{a}}$ falls due to glucagon deficiency (data not shown); at the same time, the SRIF-induced hypoinsulinemia causes a decline in $R_{d}$. However, due to relatively slow decay in insulin action, $R_{d}$ declines more slowly than $R_{a}$, and this imbalance results in a fall in the serum glucose level. To prevent this fall and maintain the serum glucose at the basal level, it is necessary to infuse glucose exogenously. At approximately $180 \mathrm{~min}, \mathrm{R}_{\mathrm{a}}$ progressively recovers (data not shown) and eventually approaches or exceeds $R_{d}$. Despite the discontinuation of the exogenous glucose infusion, this can lead to an overshoot in the serum glucose level above base line, and this phenomenon is most evident at $220 \mathrm{~min}$ in the control group (Fig. 1, top left panel). It was therefore not possible in all cases to "clamp" the serum glucose continuously at the basal value in the latter part of some of the control studies. In the NIDDM group, $\mathbf{R}_{\mathrm{a}}$ and $R_{d}$ fell during the initial part of the study, but recovery of $R_{a}$ was not as brisk and we were able to better compensate by decreasing the exogenous glucose infusion and avoid a rise in the serum glucose level above basal (Fig. 1, top right panel). Thus, to calculate steady-state rates of NIMGU, we used the data obtained during time intervals at which the serum glucose level $(101 \mathrm{mg} / \mathrm{dl})$ was within $12 \%$ of the basal value in the control group (between 120 and $200 \mathrm{~min}$ ) and within 5\% (260 $\mathrm{mg} / \mathrm{dl}$ ) of the basal value in the NIDDM group (between 120 and 200 $\mathrm{min}$ ). During these time intervals, steady-state conditions are exhibited by the stable serum glucose level and stable glucose disposal rates $\mathbf{R}_{\mathbf{d}}$ (Fig. 1, bottom). As previously stated, NIMGU can occur in insulinsensitive and nonsensitive tissues. However, it has been estimated that the great majority of NIMGU occurs in the central nervous system (CNS) (3-4), whereas muscle accounts for the preponderance of IMGU (9). Since the CNS accounts for most of NIMGU, it follows that NIMGU will not increase in proportion to overall body mass. Thus, it would seem incorrect to normalize rates of NIMGU to some aspect of body size or mass. On the other hand, since IMGU occurs predominantly in the muscle, it seems reasonable to normalize this measurement to some aspect of body mass. Based on this, we chose to express rates of NIMGU in $\mathrm{mg} / \mathrm{min}$, and $\mathrm{IMGU}$ as $\mathrm{mg} / \mathrm{kg}$ per $\mathrm{min}$.

Analytical methods. Blood for serum glucose determinations was drawn, placed in untreated polypropylene tubes, and spun using a microfuge (Beckman Instruments, Inc., Spinco Div., Palo Alto, CA). The glucose concentration of the supernatant was then measured by the glucose oxidase method using a glucose analyzer (Yellow Springs Instrument Co., Yellow Springs, $\mathrm{OH}$ ). Blood for determination of serum insulin levels and plasma glucose specific activity was collected in treated and untreated tubes, respectively, and allowed to clot. The specimens were spun and the serum was removed and stored at $-20^{\circ} \mathrm{C}$. Serum-free insulin levels and total insulin levels were measured by double antibody radioimmunoassay (10). NIDDM subjects with a history of previous insulin injections and in whom insulin antibodies were detected, had serumfree insulin levels determined. Blood for determination of serum C-peptide levels was collected in tubes containing EDTA and Trasylol (500 $\mathrm{U} / \mathrm{ml}$ ) and placed on ice; the serum was separated and frozen. The Cpeptide radioimmunoassay was kindly performed in Dr. Arthur Rubenstein's laboratory (Chicago, IL).

Data analysis. All calculations and analysis were performed using the CLINFO system of the University of California, San Diego General Clinical Research Center. Data presented represent the mean ( \pm SEM) unless otherwise stated. Statistical analysis was done using the two-tailed Student's $t$ test for paired data and unpaired data and the Wilcoxon signed rank test for nonparametric data as indicated.

\section{Results}

Serum glucose and hormone levels. The mean fasting serum glucose and insulin levels were $90 \pm 2 \mathrm{mg} / \mathrm{dl}$ and $9 \pm 2 \mu \mathrm{U} / \mathrm{ml}$ in 
controls, and $249 \pm 24 \mathrm{mg} / \mathrm{dl}$ and $17 \pm 3 \mu \mathrm{U} / \mathrm{ml}$ in the NIDDM subjects, respectively (Table I). Basal C-peptide levels were $0.55 \pm 0.06$ in the control and $1.41 \pm 0.22 \mathrm{pmol} / \mathrm{ml}$ in the NIDDM group, $P<0.01$ (Table I). During the SRIF infusion the serum insulin level dropped rapidly from basal in both groups and within the first hour, steady-state insulin levels were below the detectable limits of the assay $(<4 \mu \mathrm{U} / \mathrm{ml})$. Steady-state C-peptide measurements revealed a $>92 \%$ reduction from basal levels during the SRIF infusion, decreasing to levels of $0.025 \pm 0.002 \mathrm{pmol} /$ $\mathrm{ml}$ in controls and $0.10 \pm 0.01 \mathrm{pmol} / \mathrm{ml}$ in NIDDM. The value in the NIDDM group was still significantly greater than control, $P<0.001$. Thus, SRIF induced a profound and sustained state of severe insulin deficiency in the peripheral circulation. Since the biologic effect of insulin to stimulate glucose disposal decays with an apparent half-time of $\sim \mathbf{4 0} \mathrm{min}$ (11), it follows that after $120 \mathrm{~min}$ of absolute insulin deficiency, isotopically determined glucose disposal rate $\left(\mathbf{R}_{\mathbf{d}}\right)$ represents NIMGU.

Basal glucose disposal rates (basal insulin present). In the basal state, the serum glucose level is quite stable; therefore, the rate of overall glucose appearance $\mathbf{R}_{\mathrm{a}}$ (hepatic glucose production) must equal the rate of glucose utilization $\left(R_{d}\right)$. Because of prevailing hyperglycemia, some NIDDM subjects will exhibit glucosuria and $\mathbf{R}_{\mathbf{d}}$ must be corrected for urinary losses in order to reflect only tissue glucose disposal. Despite this correction, the basal rate of overall glucose disposal (NIMGU + IMGU) was greatly increased in NIDDM compared with control subjects, $274 \pm 31$ vs. $150 \pm 7 \mathrm{mg} / \mathrm{min}$, respectively $(P<0.01$, Fig. 1 , bottom).

As can be seen in Fig. $2 A$, the mean rate of NIMGU was $113 \pm 8 \mathrm{mg} / \mathrm{min}$ in controls, when measured at euglycemia, compared with $195 \pm 23 \mathrm{mg} / \mathrm{min}$ in NIDDMs when measured at about the mean fasting serum glucose of $249 \pm 24 \mathrm{mg} / \mathrm{dl}$. Since these rates were measured at basal glucose levels for both groups, they represent the amount of basal $R_{d}$ accounted for by NIMGU. Therefore, the NIDDM subjects have basal rates of NIMGU that are $\sim 2$ times that of control subjects.

Since basal $R_{d}$ (basal insulin present) was measured in both groups (Fig. $2 \mathrm{~B}$ ), we were also able to calculate the proportion of basal $R_{d}$ that occurs via noninsulin-mediated mechanisms; $\sim 75 \pm 5 \%$ of the basal $R_{d}$ is NIMGU in control and $71 \pm 4 \%$ in
NIDDM subjects (Fig. $2 C$ ). Thus, even though absolute rates of NIMGU are markedly increased in NIDDMs, NIMGU composes approximately the same proportion of basal $\mathbf{R}_{\mathbf{d}}$ in both groups.

If overall basal $R_{d}$ (NIMGU + IMGU) and basal NIMGU are known, then IMGU can be calculated (IMGU $=\mathbf{R}_{\mathbf{d}}$ - NIMGU). Absolute rates of basal IMGU were higher in NIDDM than in control ( $1.0 \pm 0.24$ vs. $0.70 \pm 0.3 \mathrm{mg} / \mathrm{kg}$ per min); however, these differences did not reach statistical significance $(P=0.21$; Fig. $2 D)$.

To directly compare NIMGU in control and NIDDM at a similar serum glucose level, we studied seven control subjects under hyperglycemic conditions. This was done by acutely raising the serum glucose to a mean level of $248 \pm 2 \mathrm{mg} / \mathrm{dl}$ (comparable to the mean fasting serum glucose level found in the NIDDM group) via a variable exogenous glucose infusion (Fig. 3). Again, SRIF was infused to suppress endogenous insulin release and NIMGU was measured isotopically. At all times the serum insulin levels remained suppressed to a similar degree as in the euglycemic studies, and exhibited no breakthrough; steady-state C-peptide levels were reduced by $85 \%$ of the basal value, to a mean steady-state level of $0.09 \pm 0.02 \mathrm{pmol} / \mathrm{ml}$. To acutely raise the serum glucose level, large amounts of glucose were infused over the first $60 \mathrm{~min}$, and as the serum glucose approached the desired level the glucose infusion was decreased to match the rate of glucose disposal and achieve new steady-state conditions. By 120 min the serum glucose was stable and $R_{d}$ approximated $R_{a}$; therefore, the data between 120-200 min were used to calculate NIMGU. Under these conditions (serum glucose level $=250 \mathrm{mg} / \mathrm{dl}$ ), the rate of NIMGU in the control group was $186 \pm 19 \mathrm{mg} / \mathrm{min}$.

Since NIMGU was estimated under similar conditions and at a comparable mean glucose level $(\sim 250 \mathrm{mg} / \mathrm{dl})$ in control and NIDDM subjects, we can directly compare NIMGU rates in both groups. As can be seen in Fig. 4, at a serum glucose of $\sim 250 \mathrm{mg} / \mathrm{dl}$, NIMGU was quite similar for both NIDDM and control groups, $197 \pm 14 \mathrm{mg} / \mathrm{min}$ and $186 \pm 19 \mathrm{mg} / \mathrm{min}$, respectively, $P=$ NS. This indicates that at a serum glucose level of $250 \mathrm{mg} / \mathrm{dl}$, NIMGU functions at normal efficiency in NIDDM.

Glucose clearance, via NIMGU mechanisms (NIMGU
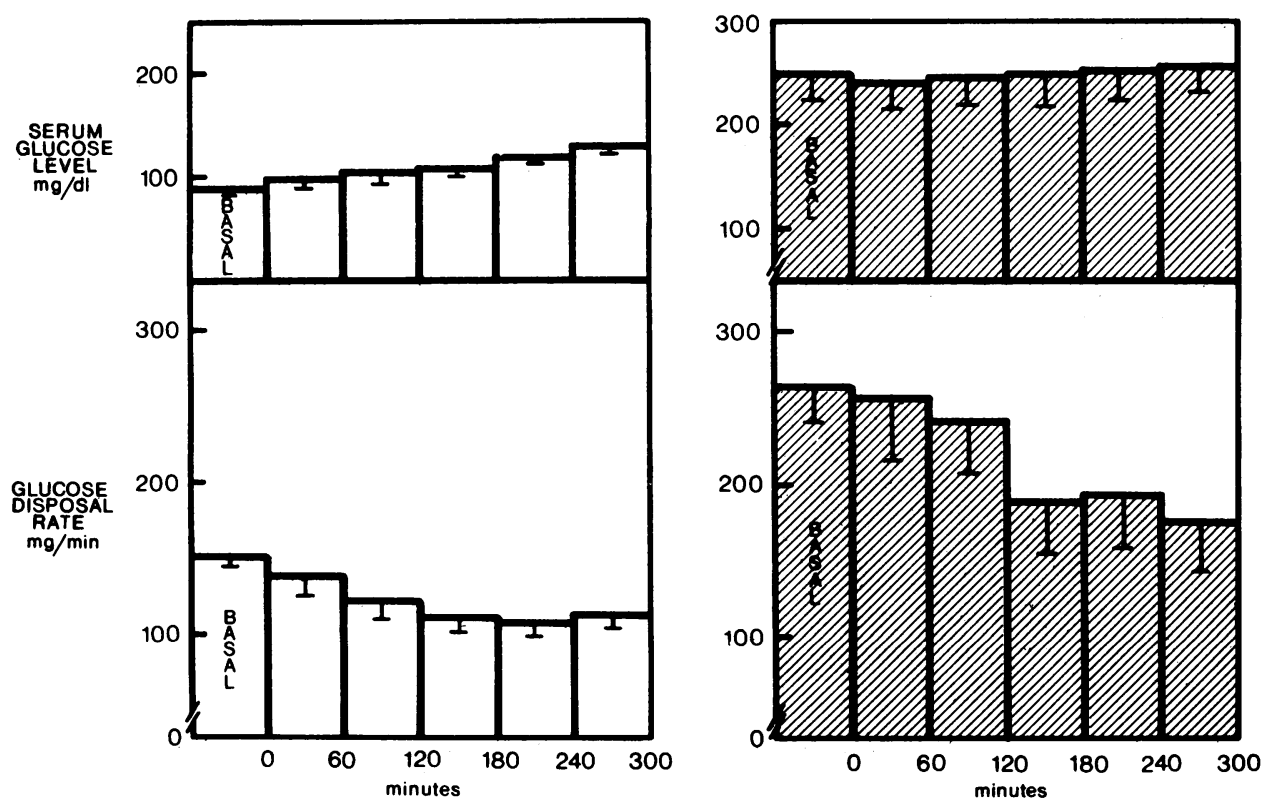

Figure 1. Serum glucose levels (top) and rates of noninsulin-mediated glucose uptake in $\mathrm{mg} / \mathrm{min}$ (bottom) during the infusion of SRIF with the serum glucose held at or near the fasting level in 11 control (open bars) and 7 NIDDM (hatched bars) subjects. Data are represented as mean \pm SEM. 


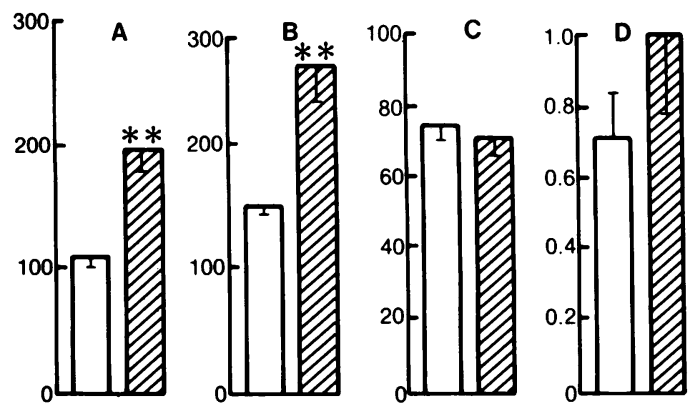

Figure 2. (A) Rates of NIMGU in $\mathrm{mg} / \mathrm{min}$ at the basal serum glucose level; $(B)$ basal rates of glucose disposal in $\mathrm{mg} / \mathrm{min} ;(C)$ rates of NIMGU as percent of the basal glucose disposal rate; and $(D)$ rates of IMGU in $\mathrm{mg} / \mathrm{kg} / \mathrm{min}$. Control subjects are in open bars, NIDDM subjects in hatched bars. ${ }^{*} P<0.05 ;{ }^{* *} P<0.01$. Data are represented as mean \pm SEM.

$\div$ serum glucose level), calculated in control subjects decreased from $1.2 \pm 0.07 \mathrm{mg} / \mathrm{dl}$ per min at a serum glucose level of $90 \mathrm{mg} /$ dl to $0.74 \pm 0.08 \mathrm{mg} / \mathrm{dl}$ per min at a prevailing serum glucose level of $248 \mathrm{mg} / \mathrm{dl}(P<0.01)$. Since we have shown that absolute rates of NIMGU were similar in control and NIDDM subjects at a mean serum glucose level of $250 \mathrm{mg} / \mathrm{dl}$, it follows that glucose clearance via NIMGU was similar in NIDDM and control subjects, $0.79 \pm 0.08 \mathrm{mg} / \mathrm{dl}$ per min compared with $0.74 \pm 0.08 \mathrm{mg} /$ dl per $\min$, respectively; $P=\mathrm{NS}$.

\section{Discussion}

Although a multitude of studies have assessed overall glucose uptake under hyperinsulinemic conditions $(12,13)$, only a few studies have examined rates of glucose uptake under conditions

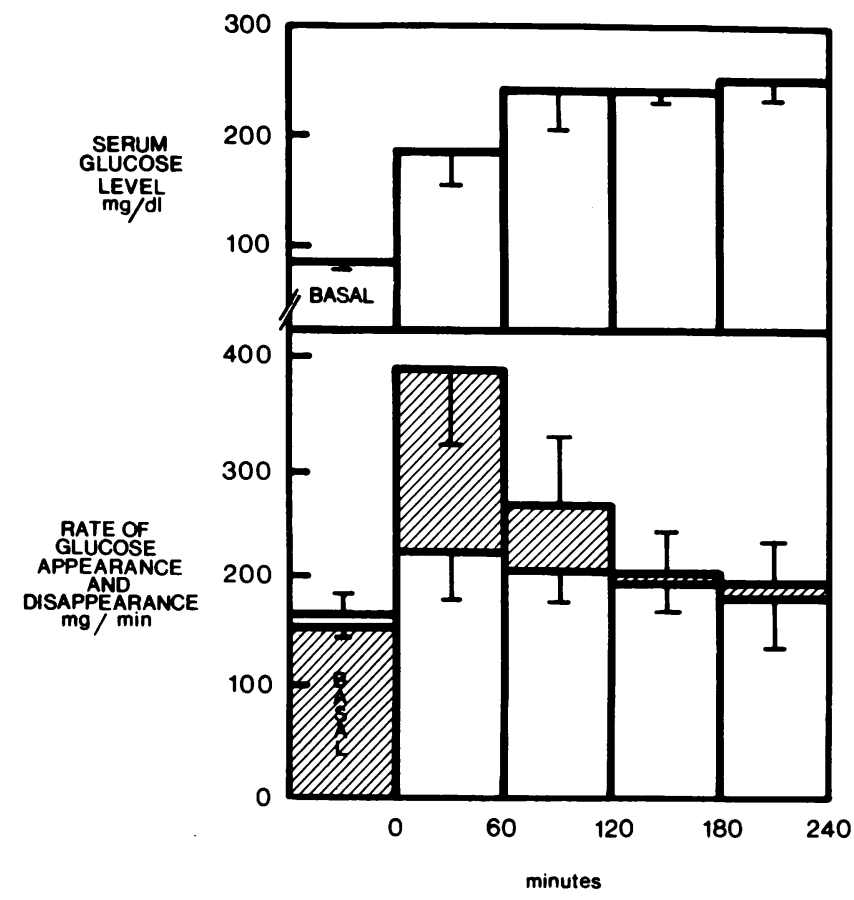

Figure 3. Rates of glucose appearance (hatched bars) and disappearance in $\mathrm{mg} / \mathrm{min}$ (open bars) in seven control subjects during SRIF infusion with the glucose level clamped at $\sim 250 \mathrm{mg} / \mathrm{dl}$ (top). Data are presented as mean \pm SEM. of insulin deficiency. Gottesman et al. (2) reported that between 75 and $85 \%$ of glucose uptake in the postabsorptive state is noninsulin-dependent in normal human subjects. However, as previously described, these estimates were obtained through extrapolation and do not reflect a direct measurement. On the other hand, Felber et al. (1) used a methodological approach similar to ours, to look at the fate of glucose metabolism in normal humans, under insulinopenic conditions, and estimated that $>80 \%$ of basal glucose uptake was independent of insulin action. However, in that study (1) NIMGU may have been overestimated, since basal peripheral insulin levels were only suppressed by $50 \%$ to $7 \mu \mathrm{U} / \mathrm{ml}$, during the SRIF infusion, and this degree of insulinemia may still stimulate glucose uptake. Furthermore, recent studies have shown that the $t^{1 / 2}$ for deactivation of insulin action on in vivo glucose disposal (i.e., time required for glucose disposal rates to decrease by $1 / 2$ after the discontinuation of an exogenous insulin infusion) is $\sim 30-50 \mathrm{~min}(10)$. Since Felber et al. (1) used data obtained as early as $40 \mathrm{~min}$ after the onset of the SRIF infusion, it is possible that some residual IMGU from the presomatostatin insulin levels still existed.

In the present study, we have directly quantitated basal rates of glucose uptake under insulinopenic conditions, in control and Type II diabetic subjects. We found that $75 \%$ of basal glucose uptake is disposed of via NIMGU mechanisms in control, and $71 \%$ in NIDDM subjects. Since the absolute rate of basal $R_{d}$ was markedly elevated in NIDDM $(274 \pm 31$ vs. $150 \pm 7 \mathrm{mg} / \mathrm{min}$, respectively), it follows that the basal absolute rates of NIMGU were also markedly elevated in the NIDDM subjects (195 \pm 23 vs. $113 \pm 8 \mathrm{mg} / \mathrm{min}$ ). However, the control subjects were studied under euglycemic conditions, whereas the NIDDM subjects were studied at hyperglycemia. Therefore, to determine the effects of hyperglycemia per se on NIMGU, the control subjects were also studied at glucose concentrations comparable to the NIDDM group $(\sim 250 \mathrm{mg} / \mathrm{dl})$. Under these conditions, absolute rates of NIMGU (Fig. 4) were nearly identical, between the two groups. These lines of evidence strongly argue that the noninsulin-mediated uptake system functions normally in NIDDM. Since it is well known that NIDDM subjects demonstrate a marked impairment in overall insulin-stimulated glucose disposal (12), it would appear that the mechanisms responsible for decreased glucose transport in NIDDM are unique to those tissues with an insulin-responsive glucose uptake system.

The glucose transport system can be described by MichaelisMenten kinetics, such that increases in glucose concentration will lead to progressively smaller increases in glucose uptake, until the transport system becomes saturated, at which point a further increase in glucose concentration will lead to no further increase in glucose transport. Several reports have described the saturability of the insulin-stimulated glucose uptake system in vivo in both normal and Type II diabetic subjects $(14,15)$, and in isolated human adipocytes (16). Gottesman et al. (2) have extrapolated that noninsulin-mediated glucose transport is also saturable. However, the only direct support for this notion comes from in vitro studies measuring glucose uptake in the absence of insulin. Though our results show that NIMGU rates do not increase proportionally with the ambient serum glucose level, these data are not sufficient to show that the entire NIMGU system is saturable. However, since the degree of fall in metabolic clearance rate is directly proportional to the fraction of total NIMGU that is saturated and thus fixed, the marked fall in glucose clearance from 90 to $250 \mathrm{mg} / \mathrm{dl}$ is consistent with the formulation that most of the saturation occurs below a prevailing 


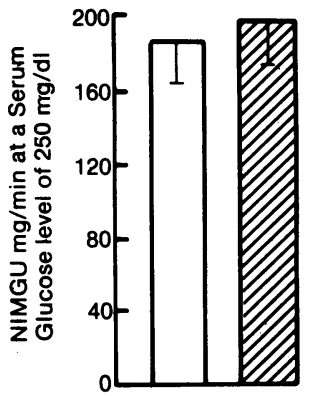

Figure 4. Rates of noninsulin-mediated glucose uptake (NIMGU) in $\mathrm{mg} / \mathrm{min}$, in seven control subjects (open bars) and seven NIDDM subjects (hatched bars) at a prevailing serum glucose level of $\sim 250$ $\mathrm{ng} / \mathrm{ml}$. Data are represented as mean \pm SEM.

serum glucose level of $90 \mathrm{mg} / \mathrm{dl}$. Note that the NIMGU system as currently defined is not a homogeneous system, but rather represents a composite of multiple noninsulin-mediated glucose uptake systems likely to have different kinetic parameters in different tissues.

In the absence of insulin, glucose uptake can occur in both insulin-sensitive (muscle, adipocytes, etc.) and noninsulin-sensitive (nervous system, splanchnic, endothelial cells, white blood cells, red blood cells, etc.) tissues, and the current studies do not allow us to distinguish which tissues account for the measured rates of NIMGU. However, there is good evidence that the brain normally accounts for $\sim 2 / 3$ of basal glucose uptake $(4,17,18)$, and since we have determined that $\sim 2 / 3$ of basal glucose uptake is noninsulin-mediated, it follows that the great majority of basal NIMGU in normal humans occurs in the CNS. This may not hold true for NIDDM subjects, where by mass action, the elevated basal glucose level may drive proportionally more glucose into insulin sensitive tissues than into noninsulin-sensitive tissues, via NIMGU mechanisms. Our studies do not directly demonstrate the tissue sites responsible for NIMGU, but it is likely that disposition of NIMGU differs in NIDDM compared with controls. For example, the major route of glucose metabolism in the CNS is oxidation $(4,17,18)$, and it has been shown recently that basal rates of overall glucose oxidation are not increased in hyperglycemic NIDDM subjects (19). This is consistent with the formulation that NIMGU into CNS tissues is comparable in normal and NIDDM subjects, and that the increase in overall NIMGU in NIDDM involves increased glucose storage or other mechanisms of glucose disposal in non-CNS tissues. For example, in normal subjects at euglycemia, only a small component of overall NIMGU is into non-CNS tissues (including insulin target and non-target tissues). However, in the presence of hyperglycemia, the mass action effect of increased glucose levels may increase glucose uptake into these non-CNS tissues. This glucose either can be stored as glycogen or other macromolecules, or alternatively, can enter the glycolytic pathway and can be broken down to three carbon fragments, which, via the Cori Cycle and/or alanine cycle, are transported back to the liver where they can enter the gluconeogenic pathway; the glucose generated can then be stored as glycogen or can reenter the circulation. Under hormonal conditions that favor gluconeogenesis, i.e., insulin resistance and relative hyperglucagonemia found in Type II diabetics, this pathway could maintain a cycle of elevated rates of hepatic glucose production with increased rates of noninsulin-mediated glycolytic metabolism in peripheral tissues and recycling of the generated lactate, pyruvate, and possibly alanine back to the liver to sustain the elevated rates of gluconeogenesis and hepatic glucose output.

If hyperglycemia in NIDDM increases nonoxidative glucose metabolism in non-CNS tissues, while CNS oxidative glucose metabolism remains normal, then since glucose oxidation is the major pathway of glucose metabolism in the CNS, it follows that the $K_{\mathrm{m}}$ for overall glucose uptake in the CNS must be substantially lower than that for non-CNS tissues (taken as a whole). Thus, due to relative saturation of CNS glucose uptake, increasing hyperglycemia will disproportionally augment glucose disposal into the non-CNS tissues. This would signify that if we could measure it, NIMGU into non-CNS tissues is increased in diabetics.

For any given serum glucose level, as one increases serum insulin levels, IMGU will increase; however, since NIDDM subjects are insulin-resistant, this increase in IMGU will be much greater in normal subjects compared with NIDDM. Our current studies show that absolute rates of IMGU are similar in both control and NIDDM subjects in the basal state. However, the determinants of the basal rate of IMGU are different in both groups. In NIDDM subjects normal rates of IMGU are achieved by means of a large "push" effect by the prevailing hyperglycemia (i.e., mass action) and by a small "pull" effect from basal insulin levels. In normal humans the reverse occurs, in that basal IMGU is a result of a relatively large insulin "pull" effect and small glucose "push" effect. This line of reasoning is consistent with a previous report from this laboratory, in which hyperglycemic clamp studies (20) were performed in Type II diabetic subjects at their respective fasting serum glucose levels over a range of insulin levels. These data showed that glucose disposal rates were superimposable on those obtained in control subjects clamped at euglycemia, over the same insulin concentrations. In view of these data, we suggested that the elevated basal rates of hepatic glucose output found in untreated Type II diabetics serve to maintain a prevailing level of hyperglycemia sufficient to compensate by mass action for the decrease in insulin effect to stimulate peripheral glucose disposal. In other words, hepatic and peripheral glucose metabolism are coupled in such a way that hepatic glucose output increases to the rate necessary to maintain the level of hyperglycemia required to compensate for the insulin resistance and thereby maintain IMGU at near normal rates. If this is the case, then for the insulin-sensitive uptake system to maintain "normal" uptake rates, the noninsulin-sensitive uptake system is subjected to high prevailing serum glucose levels with a marked increase in its rate of glucose disposal. In fact, we have found that basal rates of NIMGU in Type II diabetics were nearly twice those found in control, $195 \pm 23 \mathrm{mg} / \mathrm{min}$ vs. $113 \pm 8 \mathrm{mg} /$ min, respectively. These findings may have implications in the pathogenesis of some of the late complications of Type II diabetes.

Most basal NIMGU normally occurs in noninsulin-sensitive tissues, particularly the CNS $(4,17,18)$, and this has a critical impact on how one expresses rates of NIMGU. For example, since IMGU is known to occur principally in the muscle bed, IMGU rates should be normalized to some measure of the muscle mass or lean body weight (i.e., body weight, relative body weight, body mass index, etc.). On the other hand, in normal humans it would be more appropriate to express basal NIMGU rates normalized to brain weight or some other quantitative measure of the mass of tissue responsible for NIMGU. Since such measurements are unavailable, and since the tissues (mainly CNS) contributing to NIMGU are not proportional to body size, we have expressed NIMGU rates in total $\mathrm{mg} / \mathrm{min}$, as this avoids assigning a tissue site dependent on body size or weight. However, as discussed earlier, under hyperglycemic conditions, the mass action effect of glucose drives more glucose into NIMGU mech- 
anisms, and this may occur in insulin-independent tissues (mostly CNS) and insulin-sensitive tissues (mostly muscle), or both. Logically then, the proportion of NIMGU going to muscle should be normalized to some aspect of lean body mass and that proportion of NIMGU going to the CNS expressed as total $\mathrm{mg} / \mathrm{min}$. Since we cannot measure the relative distribution of NIMGU into different tissues under hyperglycemic conditions, we expressed all rates of NIMGU in total milligrams per minute. Note, however, that regardless of the method of data expression, the conclusions we have drawn concerning comparative NIMGU rates between normals and NIDDMS, would be unaffected.

Finally, the validity of the data presented is critically dependent on certain assumptions that should be addressed: (a) SRIFinduced insulin deficiency must be as complete as possible. In this regard, serum insulin levels measured during the SRIF infusion were below the detectable limits of the assay and C-peptide suppression was nearly complete $(>92 \%)$ in both groups when studied at their respective fasting serum glucose level and was $>85 \%$ in the control group when studied at hyperglycemia. If we assume that hepatic C-peptide extraction is negligible (21), we can estimate the actual circulating peripheral insulin level. For example, fasting insulin levels were $9 \mu \mathrm{u} / \mathrm{ml}$ and $16 \mu \mathrm{u} / \mathrm{ml}$ in control and NIDDM subjects. Since C-peptide was suppressed by $92 \%$ in both groups this would result in actual peripheral insulin levels of $<1 \mu \mathrm{u} / \mathrm{ml}$ and $<2 \mu \mathrm{u} / \mathrm{ml}$ in control and NIDDM groups, respectively. Likewise, the control group studied at hyperglycemia would be expected to have had a circulating peripheral insulin level of $<2 \mu \mathrm{u} / \mathrm{ml}$. Therefore, it is highly unlikely that any IMGU existed during the SRIF infusions. (b) SRIF must not affect peripheral glucose uptake. This assumption seems reasonable, since several in vitro and in vivo reports have failed to show any effect of SRIF on glucose disposal at the doses used in this study (22). A recent report by Bergman et al. (23) suggests that SRIF may have an intrinsic effect on glucose uptake. Indeed, they showed a $65 \%$ increase in glucose clearance when SRIF was infused into dogs at a rate of $0.8 \mu \mathrm{g} / \mathrm{kg}$ per min. Note that this dose of SRIF is seven times greater on a per kilogram basis, than that employed in our study. Thus, it is unlikely that SRIF had any significant effect on glucose uptake under the study conditions used. (c) SRIF-induced growth hormone and glucagon deficiency must not affect peripheral glucose uptake. The available data indicate that glucagon has no effect on peripheral glucose uptake (24) and that short-term $(<6 \mathrm{~h})$ growth hormone (GH) deficiency does not alter basal glucose disposal (25). Finally, (d) NIMGU measured after $200 \mathrm{~min}$ of insulin deficiency must reflect that component of basal glucose uptake that is noninsulinmediated. It is indeed possible that insulin deficiency induces changes in flux of certain metabolites, such as free fatty acids, amino acids, or other changes, which may affect glucose uptake, making it difficult to accurately assess the true basal physiologic NIMGU rate. We have good reason, however, to believe that our measurements accurately reflect basal physiologic NIMGU. We have estimated that NIMGU represents $\sim 75 \%$ of overall basal glucose utilization in control subjects. These data are in good agreement with those of Gottesman et al. (2) who derived glucose uptake at " 0 " insulin by plotting glucose disposal vs. plasma insulin levels and extrapolated to the intercept for glucose disposal at " 0 " insulin. Though this method assumes linearity of glucose uptake over insulin levels lower than that employed in the study, this assumption is likely to be valid based on data from several in vitro studies $(26,27)$ showing glucose uptake to be linear over insulin concentrations ranging from 0 to $25 \mu \mathrm{u} /$ ml. In addition, numerous reports have estimated CNS (a noninsulin-sensitive tissue) glucose uptake to represent $>70 \%$ of total basal glucose uptake $(4,17,18)$. These estimates were derived using methods that did not alter the physiologic milieu. In addition, available data from Ferrannini et al. (28) and Thiebaud et al. (29) indicate that a two- to fourfold rise in the free fatty acid (FFA) level from basal is required to cause a $\sim 20 \%$ decrease in insulin-stimulated glucose uptake in normal subjects. Felber et al. (1) have shown that the infusion of $600 \mu \mathrm{g} / \mathrm{h}$ of somatostatin (the dose used in this study) produced only a twofold rise in FFA levels in control subjects. Thus, it is unlikely that a rise in FFA levels significantly affected rates of noninsulin-mediated glucose uptake measured in our study. Recent reports $(30,31)$ have shown that the infusion of the amino acids leucine, isoleucine, and threonine to achieve high physiological serum concentrations significantly decreased forearm insulin-stimulated glucose uptake in humans. However, these same authors were not able to show any decrease in whole body glucose uptake during the infusion of each of these amino acids. This indicates that the decrease in forearm glucose uptake during amino acid infusion was very small when compared with overall glucose disposal, and therefore, could not be detected. Thus, changes in amino acid levels are not likely to have significantly altered our measurements of NIMGU. As with a rise in FFA levels, a rise in amino acid levels would have the net effect of decreasing glucose uptake. Therefore, although we do not believe that changes in FFA or amino acid levels have significantly affected our measurements of NIMGU, if indeed they had, then our measurements would represent underestimates of the true rates of NIMGU.

In summary, the results of this study document that the majority of basal glucose uptake occurs via noninsulin-mediated glucose uptake mechanisms. Furthermore, noninsulin-mediated glucose uptake seems to function normally in Type II diabetic subjects. Finally, Type II diabetics have basal rates of noninsulinmediated glucose uptake that are approximately twice normal and this may play a role in the pathogenesis of the late complications of Type II diabetes.

\section{Acknowledgments}

The authors wish to thank P. Elliott and R. Thorne for their expert technical assistance and Cleon Tate and Elizabeth Martinez for their expert secretarial assistance.

This work was supported in part by grants AM 33652 from the National Institutes of Arthritis, Metabolism, and Digestive Diseases branch of the National Institutes of Health; RR-00827 from the Clinical Research Center branch of the National Institutes of Health, and the Juvenile Diabetes Foundation. Dr. Baron is the recipient of a Juvenile Diabetes Foundation Postdoctoral Fellowship Award.

\section{References}

1. Felber, J. P., D. Thiebaud, E. Maeder, E. Jequier, R. Hendler, and R. A. DeFronzo. 1983. Effect of a somatostatin-induced insulinopenia on glucose oxidation in man. Diabetologia 25:325-330.

2. Gottesman, I., L. J. Mandarino, and J. Gerich. 1983. Estimation and kinetic analysis of insulin independent glucose uptake in human subjects. Am. J. Physiol. 2244(6):E6322-E6325.

3. Cahill, G. F., and O. E. Owen. 1968. Some observations on carbohydrate metabolism in man. In Carbohydrate Metabolism and its disorders. F. Dichens, P. J. Randle, and W. J. Whelan, editors. Academic Press, Inc., New York. 497-522. 
4. Huang, S. C., M. E. Phelps, E. J. Hoffman, K. Sideris, C. J. Selin, and D. E. Kuhl. 1980. Noninvasive determination of local cerebral metabolic rate of glucose in man. Am. J. Physiol. 238:E69-E82.

5. National Diabetes Data Group. 1979. Classification and diagnosis of diabetes mellitus and other categories of glucose intolerance. Diabetes. 28:1039-1057.

6. Defronzo, R. A., T. D. Tobin, and R. Andres. 1979. Glucose clamp technique: a method for quantifying insulin secretion and resistance. Am. J. Physiol. 327:E214-E223.

7. Steele, R. 1959. Influence of glucose loading and injected insulin on hepatic glucose output. Ann. NY Acad. Sci. 82:420-430.

8. Sherwin, R. S., R. Hendler, R. DeFronzo, J. Wahren, and P. Felig. 1977. Glucose homeostasis during prolonged suppression of glucagon and insulin secretion by somatostatin. Proc. Natl. Acad. Sci. 74:318352.

9. DeFronzo, R. A., and R. Gunnarsson. 1982. Peripheral tissues are responsible for the insulin resistance in non-insulin dependent diabetes mellitus. Diabetes. 40(Suppl):No. 10.

10. Desbuquois, B., and G. D. Aurbach. 1921. Use of polyethylene glycol to separate free and antibody bound peptide hormones in radioimmunoassays. J. Clin. Endocrinol. Metab. 33:732-738.

11. Gray, R. S., S. A. Scarlett, J. Griffin, J. M. Olefsky, and O. G. Kolterman. 1982. In vivo deactivation of peripheral, hepatic and pancreatic insulin action in man. Diabetes. 31:929-936.

12. Kolterman, O. G., R. S. Gray, J. Griffin, P. Burstein, J. Insel, J. A. Scarlett, and J. M. Olefsky. 1981. Receptor and postreceptor defects contribute to the insulin resistance in noninsulin-dependent diabetes mellitus. J. Clin. Invest. 68:957-969.

13. Rizza, R. A., L. J. Mandarino, and J. F. Gerich. 1981. Dose response characteristics for effects of insulin on production and utilization in man. Am. J. Physiol. 240:E630-E639.

14. Gottesman, I., L. Mandarino, C. Verdonk, R. Rizza, and S. Gerich. 1982. Insulin increases the maximum velocity for glucose uptake without altering the Michaelis constant in man. J. Clin. Invest. 70:13101314.

15. Revers, R. R., O. G. Kolterman, and J. M. Olefsky. 1985. Relationship between serum glucose level and the metabolic clearance rate of glucose in noninsulin dependent diabetes mellitus. Diabetes. 32(7): 327-332.

16. Ciaraldi, T., O. G. Kolterman, J. Siegel, and J. M. Olefsky. 1979. Insulin stimulated glucose transport in human adipocyte. Am. J. Physiol. 236:E621-E6225.

17. Scheinberg, F. P. 1965. Observations on cerebral carbohydrate metabolism in man. Ann. Intern. Med. 62:367-371.

18. Owen, O. E., A. P. Morgan, H. G. Kemp, J. M. Sullivan, M. G.
Herrera, and G. F. Cahill. 1967. Brain metabolism during fasting. $J$. Clin. Invest. 46:1589-1595.

19. Bogardus, C., S. Lillioja, B. V. Howard, G. Reaven, and D. Mott. 1984. Relationships between insulin secretion, insulin action, and fasting plasma glucose concentration in nondiabetic and noninsulin-dependent diabetic subjects. J. Clin. Invest. 74:1238-1246.

20. Revers, R. R., R. Fink, J. Griffin, J. M. Olefsky, and O. G. Kolterman. 1984. Influence of hyperglycemia on insulin's in vivo effects in Type II diabetes. J. Clin. Invest. 73:664-672.

21. Polonsky, K., J. Jaspan, W. Pugh, D. Cohen, M. Schneider, T. Schwartz, A. R. Moosa, H. Tager, and A. H. Rubenstein. 1983. Metabolism of C-peptide in the dog. In vivo demonstration of the absence of hepatic extraction. J. Clin. Invest. 72:1114-1123.

22. Cherrington, A. D., M. D. Caldwell, M. R. Dietz, J. H. Exton, and O. B. Crofford. 1977. The effect of somatostatin on glucose uptake and production by rat tissue in vitro. Diabetes. 26:740-747.

23. Bergman, R. N., M. Ader, D. T. Finegood, and G. Pacini. 1984. Extrahepatic effect of somatostatin infusion to increase glucose clearance. Am. J. Physiol. 247:E370-E379.

24. Cherrington, A. D., J. L. Chiasson, T. E. Liljeuquist, A. S. Jennings, V. Keller, and W. W. Lacy. 1976. The role of insulin and glucagon in the regulation of basal glucose production in the post absorptive dog. J. Clin. Invest. 57:875-884.

25. Gerich, T. E., M. Lorenzi, D. M. Bier, E. Tsalikian, V. Schneider, J. H. Karam, and P. H. Forsham. 1976. Effects of physiologic levels of glucagon and growth hormone on human carbohydrate and lipid metabolism. J. Clin. Invest. 57:875-884.

26. Ciaraldi, T., O. Kolterman, T. Siegal, and J. Olefsky. 1979. Insulin stimulated glucose transport in human adipocytes. Am. J. Physiol. 236: E621-E625.

27. Berhanu, P., and J. Olefsky. 1981. Effects of insulin and insulinlike agents on the glucose transport system of cultured human fibroblasts. Diabetes. 30:523-529.

28. Ferrannini, E., E. J. Barrett, S. Bevilacqua, and R. A. DeFronzo. 1983. Effect of fatty acids on glucose production and utilization in man. J. Clin. Invest. 72:1737-1747.

29. Thiebaud, D., R. A. DeFronzo, E. Jacot, A. Golay, K. Acheson, E. Maeder, E. Jequier, and J. P. Felber. 1982. Effect of long chain triglyceride infusion on glucose metabolism in man. Metab. Clin. Exp. 31: 1128-1136.

30. Schwenk, W. F., and J. M. Miles. 1984. Decreased forearm uptake of glucose during amino acid infusion. Diabetes. 31:192(Abstr.).

31. Schwenk, W. F., and M. Haymond. 1985. Glucose uptake across the forearm supplemented by isoleucine or threonine uptake. Diabetes. 34:326(Abstr.). 